\title{
LAMELLAR KERATOPLASTY* A NEW CORNEAL SPLITTING INSTRUMENT
}

BY

\section{J. HORTON YOUNG \\ Nottingham}

THIS new aid to corneal grafting has been designed to facilitate and simplify the operative procedure of lamellar keratoplasty.

The instrument, a combination of blunt dissector and a cutting knife, has been used successfully as the basis of the new splitting technique in which an exact replica of the corneal disc removed from the recipient globe can be matched and replaced by a similar disc of corneal graft tissue taken from the donor cornea.

Fig. 1 shows the stainless steel non-slip handle and blade. The latter is divided into three parts: a domed "partially" cutting snake's head; a short narrow bevelled neck; and a longer body similarly bevelled which ends abruptly in an acute-angled "heel" by which the blade is joined to the handle. The blade is curved to the same degree as the cornea. When in use the instrument is quite rigid without whip or torque and is beautifully balanced.

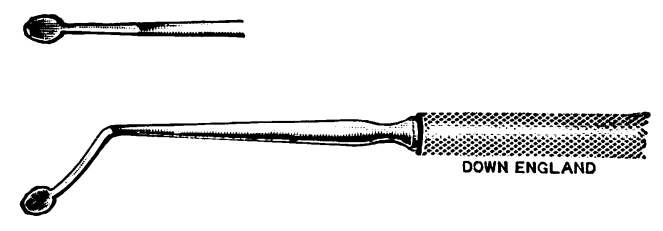

Fig. 1.-Lateral and superior aspects of corneal splitter. $\quad \times 2$.

The blade is so designed that when the head is introduced into the cornea through a predetermined limbal depth incision, its bevelled shape puts tension on the internal corneal lamellar structure so that splitting of the cornea takes place in the same plane throughout the whole area which is to be split.

\section{Operative Procedure}

(A) TABLE.-Standard instruments as for corneal grafting with addition of those atraumatic needles and sutures favoured by the surgeon. I prefer to use the Tudor Thomas Donor Graft Stand, as there is plenty of room for manoeuvre with the new corneal splitter at the limbus. 
(B) Operative TechniQue

(a) Limbal Depth Marking.-The essentials of the operation are that the recipient and the donor corneae are prepared for corneal splitting by making a limbal incision with a $5.0 \mathrm{~mm}$. trephine, the blade of which has been set to a corneal depth of $0.3 \mathrm{~mm}$. This thickness of cornea will remove most scars suitable for lamellar keratoplasty, but the actual corneal depth may be varied to suit the surgeon's needs. With the lamellar depth set at $0.3 \mathrm{~mm}$., the thickness of the floor of the graft bed in the central part of the cornea will be $0.27 \mathrm{~mm}$., the difference between the actual corneal thickness $(0.57 \mathrm{~mm}$.) and the thickness of the disc removed (0.30 mm.).

(b) Pre-setting Corneal Grafting Trephine.-It is wise at this stage to set the corneal grafting trephine blade at the same depth as that of the limbal trephine for corneal splitting, so that when graft trephination is done at a later stage the operation can proceed smoothly. Any width of graft trephine blade can be used from 4.5 to $11 \mathrm{~mm}$. For all general purposes the $6.0 \mathrm{~mm}$. graft is as effective as any and only needs superficial cross-over sutures as devised by Tudor Thomas. These sutures are usually put in before splitting the cornea, due allowance being made for the fact that they must be placed obliquely in relation to the limbal trephine wound.

(c) Special Note.-Under no circumstances must a central corneal graft or graft bed delineation be done until after the corneal splitting has been performed.

\section{(C) Splitting the Corneal Lamella}

(a) Recipient Cornea.-The head of the blade is introduced into the corneal stroma through the incision made by the depth-limiting trephine at the limbus. Keeping the "heel" well down and the "head" of the instrument gently moving to and fro and forwards, seeking the light as it were (or as a snake poised to strike), the corneal lamella is split to a slightly greater width than that required by the size of the graft trephine blade. It is surprising how simply and smoothly this is done.

(b) Donor Cornea.-With the donor globe set up in a Tudor Thomas Donor Graft Stand, using two stitches for immobilization with an assistant who further immobilizes the globe by wrapping a little gauze about it and holding it between thumb and forefinger, the whole operative procedure is repeated.

It must be remembered that many globes submitted for corneal grafting are softish.

In these two procedures the very same instruments are used for the recipient cornea as for the donor eye.

\section{(D) Preparing the Graft “Bed” and the Graft}

(a) Both globes having undergone corneal splitting, the actual preparation of the graft "bed" and of the graft to be placed in it is simplicity itself. The central area of the recipient cornea is trephined with the graft trephine, already preselected for width of blade and pre-set for a lamellar depth of $0.3 \mathrm{~mm}$. The resulting "scone" of corneal tissue is removed and is replaced by:

(b) A similar "scone" of tissue-the actual graft-from the donor cornea which has been taken in a similar manner.

The corneal sutures are now tied over the graft as it lies in its corneal "bed". A mydriatic is instilled together with antibiotic ointment, and a subconjunctival 
injection of cortisone 1 per cent. is given. The patient is double padded. A gentle pressure bandage is applied to the operated eye as a precaution.

\section{Post-operative Treatment}

(a) Leave dressings for 48 hours and then instil a mydriatic (be careful, because many cases are atropine-sensitive) and antibiotic ointment each day.

(b) "Beta" ray is given on the 18th day.

(c) Stitches are taken out on the 16th day.

\section{Post-operative Appearance}

Reaction by the host cornea to the donor graft is greatly reduced by this procedure. A typical result is seen in Fig. 2.

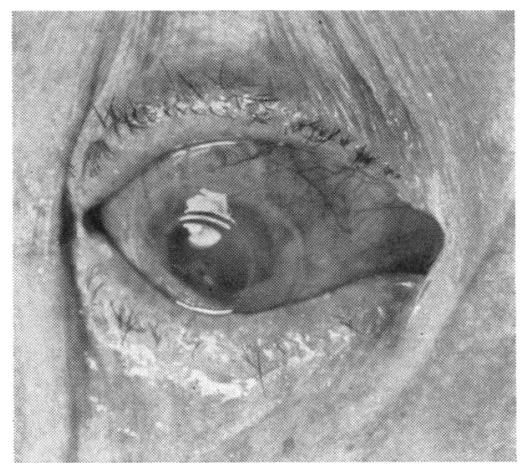

FIG. 2.-Post-operative appearance of a woman aged 60 after intralamellar keratoplasty. A $6 \times 0.3 \mathrm{~mm}$. graft was taken from an enucleated eye on the 6th day. The donor globe had been preserved in liquid paraffin at $4^{\circ} \mathrm{C}$. Note clarity of graft 22 days after the operation.

In accordance with the usual practice, clinical cases and the actual instrument will be demonstrated at a meeting of the Midland Ophthalmological Society at Nottingham.

I am greatly indebted to Down Bros. and Mayer and Phelps Ltd., for making this instrument to the specifications submitted. 